\title{
Fiebre manchada de las montañas rocosas en un hospital pediátrico en el noreste de México
}

\author{
Miguel Á. Martínez-Medina* \\ Departamento de Enseñanza e Investigación, Hospital Infantil del Estado de Sonora, Hermosillo, Sonora, México
}

He leído con gran interés el trabajo acerca de la experiencia en el tratamiento de la fiebre manchada de las montañas rocosas (FMMR) en un hospital infantil de Saltillo, Coahuila', el cual reporta hechos relevantes que permiten opinar sobre aspectos de la enfermedad en nuestro medio. En términos generales, el panorama reportado es similar a la experiencia sonorense. La enfermedad, negada durante el año 2003, ha pasado a ser una cruel realidad debido a su elevada letalidad. El estudio de los casos y entendimiento de los condicionantes sociodemográficos ha permitido identificar los factores que explican, en parte, los casos graves y defunciones por este padecimiento.

Los hallazgos de Bustamante y Ortiz Mariote en la década de 1940, que confirmaban la existencia de la fiebre manchada americana y la identificación de la garrapata café del perro Rhipicephalus sanguineus, así como la letalidad del $80 \%$ reportada en un brote en Álamos durante 1948, son los antecedentes históricos de la reemergencia de este padecimiento en Sonora a partir de la primera década del siglo $\mathrm{XXI}^{2}$.

La FMMR por Rickettsia rickettsii es, sin duda, un reto diagnóstico y el manejo hospitalario de las formas graves es un gran desafío médico. En particular, considero que el tratamiento de FMMR ha sido abordado casi exclusivamente como una infección bacteriana sujeta a la administración de un antibiótico (doxiciclina), restándole importancia a las alteraciones fisiológicas a nivel de los líquidos y volúmenes corporales, entre los que destacan el incremento del agua extracelular e intersticial, la secreción excesiva de la hormona antidiurética y un mayor volumen plasmático. Por esto, su elevada letalidad ha sido atribuida tanto a la virulencia de la rickettsia como a la tardanza en el inicio de su tratamiento. Incluso, se habla de deficiencias enzimáticas en los pacientes que no sobreviven.

Sin embargo, un análisis de casos reciente, en contraste, reporta una mortalidad elevada en casos diagnosticados en etapa temprana que habían recibido, además, un tratamiento adecuado con doxiciclina ${ }^{3}$.

La experiencia ha enseñado que después de la reanimación con bolos de cristaloides, los pacientes en choque por rickettsiosis frecuentemente evolucionan con signos de sobrecarga a nivel respiratorio, cardíaco o encefálico, y más del $60 \%$ fallece dentro de las primeras $72 \mathrm{~h}$ de hospitalización. A este respecto, un estudio en niños con esta enfermedad confirmó que la administración de cargas de líquidos se asocia significativamente con secuelas neurológicas o fallecimiento del paciente ${ }^{4}$. Por otra parte, Maitland, et al. ${ }^{5}$, en 2011, reportaron que la reanimación con bolos de solución salina o albúmina está asociada con un incremento significativo de muerte en un grupo de niños africanos con procesos infecciosos graves, comparado con otro grupo de niños que solo recibió líquidos de mantenimiento $(2.5-4 \mathrm{ml} / \mathrm{kg} / \mathrm{h})$.

A pesar de estos hallazgos, las actualizaciones más recientes de la campaña Sobreviviendo a la Sepsis y de la guía PALS (Pediatric Acute Life Support) no han modificado el tratamiento para la reanimación del
Correspondencia:

*Miguel Ángel Martínez Medina

E-mail: miguel.martinezme296@gmail.com
Disponible en internet: 18-03-2019

Fecha de aceptación: 07-01-2019

DOI: 10.24875/BMHIM.19000178 
paciente mediante bolos de soluciones a razón de 20 a $60 \mathrm{ml} / \mathrm{kg}$ en los primeros $15 \mathrm{~min}$ de manejo ${ }^{6}$. No obstante, el grupo de expertos de la Organización Mundial de la Salud (OMS), en su reporte sobre el manejo del niño críticamente enfermo 2016, introduce cambios importantes para el tratamiento del choque con signos de hipoperfusión grave (llenado capilar $>3 \mathrm{~s}$, hipotermia distal y pulso débil o ausente) $)^{7}$ y no únicamente la presencia de hipotensión arterial. La OMS recomienda la administración de cristaloides en bolos de 10-20 ml/kg durante 30 a $60 \mathrm{~min}$, así como la revaloración del caso $y$, de ser necesario, la consideración de una segunda carga de soluciones a razón de $10 \mathrm{ml} / \mathrm{kg}$ en $30 \mathrm{~min}^{7}$.

En la literatura actual se observa un renovado interés para establecer la eficacia y seguridad de protocolos con líquidos restringidos para el manejo de niños en choque. Aunque sus resultados sean a futuro, los hallazgos de Maitland, et al. ${ }^{5}$ y las recomendaciones de la OMS deben ser tomados en cuenta mediante la estimación adecuada de la gravedad del caso particular, el manejo juicioso de los líquidos de reanimación y la vigilancia constante del paciente, con el propósito de disminuir, en lo posible, los efectos nocivos de la sobrecarga de líquidos.

\section{Bibliografía}

1. López-Castillo DC, Vaquera-Aparicio D, González-Soto MA, Martínez-Ramírez R, Rodríguez-Muñoz L, Solórzano-Santos F. Fiebre manchada de montañas rocosas: experiencia en 5 años de vigilancia activa en un hospital pediátrico de segundo nivel en el noreste de México. Bol Med Hosp Infant Mex. 2018;75:303-8.

2. Martínez-Medina MA. Antecedentes históricos de la fiebre manchada de las Montañas Rocosas en Sonora. Bol Clin Hosp Infant Edo Son. 2009;26:78-82.

3. Delgado-De la Mora J, Licona-Enríquez JD, Leyva-Gastélum M, Delgado-De la Mora D, Rascón-Alcántar A, Álvarez-Hernández G. A fatal case series of Rocky Mountain spotted fever in Sonora, México. Biomédica. 2018;38:69-76.

4. Buckingham SC, Marshall GS, Schutze GE, Woods CR, Jackson MA, Patterson LE, et al. Clinical and laboratory features, hospital course, and outcome of Rocky Mountain spotted fever in children. J Pediatr. 2007;150:180-4.

5. Maitland K, Kiguli S, Opoka R, Engoru CH, Olupot OP, Akech S, et al Mortality after fluid bolus in African children with severe infection. N Engl J Med. 2011;364:2483-95.

6. Gelbart B. Fluid bolus therapy in pediatric sepsis: current knowledge and future direction. Front Pediatr. 2018;6:308-15.

7. World Health Organization [Internet]. Updated guideline: pediatric emergency triage, assessment and treatment: care of critically-ill children; 2018. Disponible en: https://www.who.int/maternal_child_adolescent/documents/paediatric-emergency-triage-update/en/ 